\title{
An epidemic of silicosis among former denim sandblasters
}

\author{
M. Akgun*, O. Araz*, I. Akkurt”, A. Eroglu^, F. Alper ${ }^{+}$, L. Saglam*, A. Mirici ${ }^{\S}$, \\ M. Gorguner* and B. Nemery ${ }^{f}$
}

ABSTRACT: Sandblasting denim using silica has emerged as a new cause of silicosis in Turkey. Following the discovery of several cases of silicosis in (young) workers who used this process, the frequency and main occupational risk factors of silicosis among former denim sandblasters in the region of Erzurum (Turkey) were evaluated.

Demographic characteristics and information on working conditions were obtained by questionnaire and interview. In addition, spirometry testing was performed and chest radiographs were evaluated according to International Labour Office (ILO) classification of pneumoconioses in 157 former denim sandblasters.

All subjects were male, with a mean (range) age of 23 (15-44) yrs. They had worked for a mean (range) of 36 (1-120) months, starting employment at a 17 (10-38) yrs of age. Most subjects (83\%) had respiratory symptoms, especially dyspnoea (52\%) but also chest pain (46\%). Radiological evidence of silicosis (ILO score 1/0 or higher) was present in 77 (53\%) out of 145 subjects with interpretable chest radiographs. These subjects had lower forced expiratory volume in one second and forced vital capacity. The risk of silicosis correlated with seniority (i.e. working as a foreman), exposure duration and number of places of work.

Considering the high prevalence rate of silicosis in such workplaces, further problems are inevitable in the future unless effective measures are taken.

KEYWORDS: Denim, jean, sandblasting, silicosis, textile industry, Turkey

ilicosis is an ancient and well-known occupational lung disease caused by inhalation of free crystalline silica. Certain occupations expose the individual to high concentrations of silica, which is fibrogenic to the lungs, resulting in radiographical and pathological abnormalities. Although silicosis is considered to be a preventable condition, it continues to occur worldwide, especially in low-income countries with a high tuberculosis (TB) burden but it is also still reported in highincome countries [1-3].

Workers engaged in occupations such as tunnelling, mining, sandblasting and quarrying are inevitably exposed to silica-containing minerals due to their ubiquity in the earth's crust. Besides these well-known sources of silica, there are many other less well-known sources [4]. Newer, sometimes unusual or unexpected, sources of silicosis continue to be reported: for example, exposure to fine dust from heat-dried mud used in tatami mat manufacturing in China [5] and dental supply factory workers using quartz- and cristobalite-containing fillers in the USA [6]. Recently, exposure to silica in the textile sector has been reported as a novel and unusual source of silicosis in Turkey, as a result of sandblasting denim (or jeans) [7].

In denim sandblasting, workers are exposed to silica because they project silica-containing sand, as an abrasive, onto denim surfaces to produce a "worn-out" appearance. This form of exposure appears to be more hazardous than many previously known sources, presumably because of very intense exposure due to long working hours, under very poor hygiene conditions without any serious respiratory protection.

After the diagnosis of the first two cases of silicosis in 2004 [7], the number of cases investigated at the Atatürk University (University School of Medicine, Aziziye Research Hospital, Dept of Chest Diseases, Erzurum, Turkey) showed a rapid increase in the following years: four cases in 2005, 27 cases in 2006 and 42 cases up to July 2007. Some of these initial cases, including two teenagers who died of silicosis, have been published previously [8, 9]. In addition, reports of new cases have continued to be made from other centres in Turkey [9-11].

\section{AFFILIATIONS}

Depts of ${ }^{*}$ Chest Diseases,

"Chest Surgery,

+Radiology, Atatürk University, Erzurum,

\#Dept of Chest Diseases, Cumhuriyet University, Sivas,

${ }^{\S}$ Dept of Chest Diseases, 18 Mart University, Canakkale, Turkey. ${ }^{f}$ Dept of Public Health, Katholieke Universiteit Leuven, Leuven, Belgium.

CORRESPONDENCE

M. Akgun

Aziziye Arastirma Hastanesi Gogus Hastaliklari Anabilim Dali 25070 Palandoken Erzurum Turkey Fax: 904423166340 E-mail: akgunm@gmail.com

Received:

July 242007

Accepted after revision: June 092008

STATEMENT OF INTEREST None declared 
All of the current authors' patients with silicosis had worked in industrial cities outside of Erzurum, e.g. in Istanbul 1,224 km to the West of Erzurum (fig. 1). The total number of workshops, many of which were unregistered, and the number of workers at risk were unknown. However, according to the current authors' patients, there were hundreds of such workplaces in Istanbul and in the Eastern part of Turkey alone, there were several hundreds of former workers.

In the present study, ex-workers in Erzurum were contacted to estimate the frequency of silicosis among them, to better characterise the extent of the problem, and to obtain more reliable data about the workplaces and working conditions.

\section{MATERIALS AND METHODS}

\section{Study population}

In the current study, the origins of the cases were determined based on the records of the outpatient clinic at Atatürk University. Although there were some cases from Erzurum and two adjacent cities, Bingöl and Kars, $>90 \%$ of the cases were from Bingöl, especially from Karliova (a county of Bingöl). These cases were mostly from two villages: Taşliçay and Toklular (within Karliova). Therefore, these two villages with a total population of 2,281 (450 households) were selected for further case finding. With the collaboration of the Mayor of Karliova, the villagers were informed about the association of sandblasting jeans and silicosis and all those who had ever worked in sandblasting workshops were invited to the outpatient clinic at Aziziye Research Hospital, with free transport being provided (the clinic lies 102 and $105 \mathrm{~km}$ from Toklular and Taşliçay, respectively). The recruitment lasted from May 1, 2007 to June 20, 2007. In these two villages alone, $\sim 500$ males, i.e. at least one person from each household, were estimated to have been employed in this sector. However, not all potential subjects participated in the survey as some had already applied to Atatürk University or other healthcare centres previously, some were serving their mandatory military service (the age of recruitment is $20 \mathrm{yrs}$ ) and some had moved out of the city in order to make a living. The study included 14 out of 49 previously diagnosed cases who had applied to Atatürk University Hopsital healthcare centre previously. All the participants gave their written informed consent, and the study protocol was approved by the local ethics committee of the School of Medicine, Atatürk University.

\section{Study procedure}

The procedure involved four steps. First, a standard questionnaire was administered to determine the age, smoking history, symptoms, age at first exposure to sandblasting, total exposure duration, duration since first exposure, the number of places of work, number of sandblasting devices used in the workplace, status at work (i.e. chief foreman, foreman or apprentice), time spent at work, types of protective measures taken and whether they slept at the workplace. In the questionnaire, the symptoms that had started after exposure and had existed for $\geqslant 1$ month before the study were questioned. Dyspnoea was defined as recurrent difficulty in breathing or shortness of breath at rest or with exertion. Chronic cough was defined as cough with or without sputum production present for $\geqslant 2$ months.

Secondly, a personal interview was conducted with each of the participants to obtain additional information such as working conditions, which were not included in the questionnaire.

Thirdly, a pulmonary function test was carried out using a computerised spirometer (Vmax22; SensorMedics Corp., Yorba Linda, CA, USA). Forced expiratory volume in one second

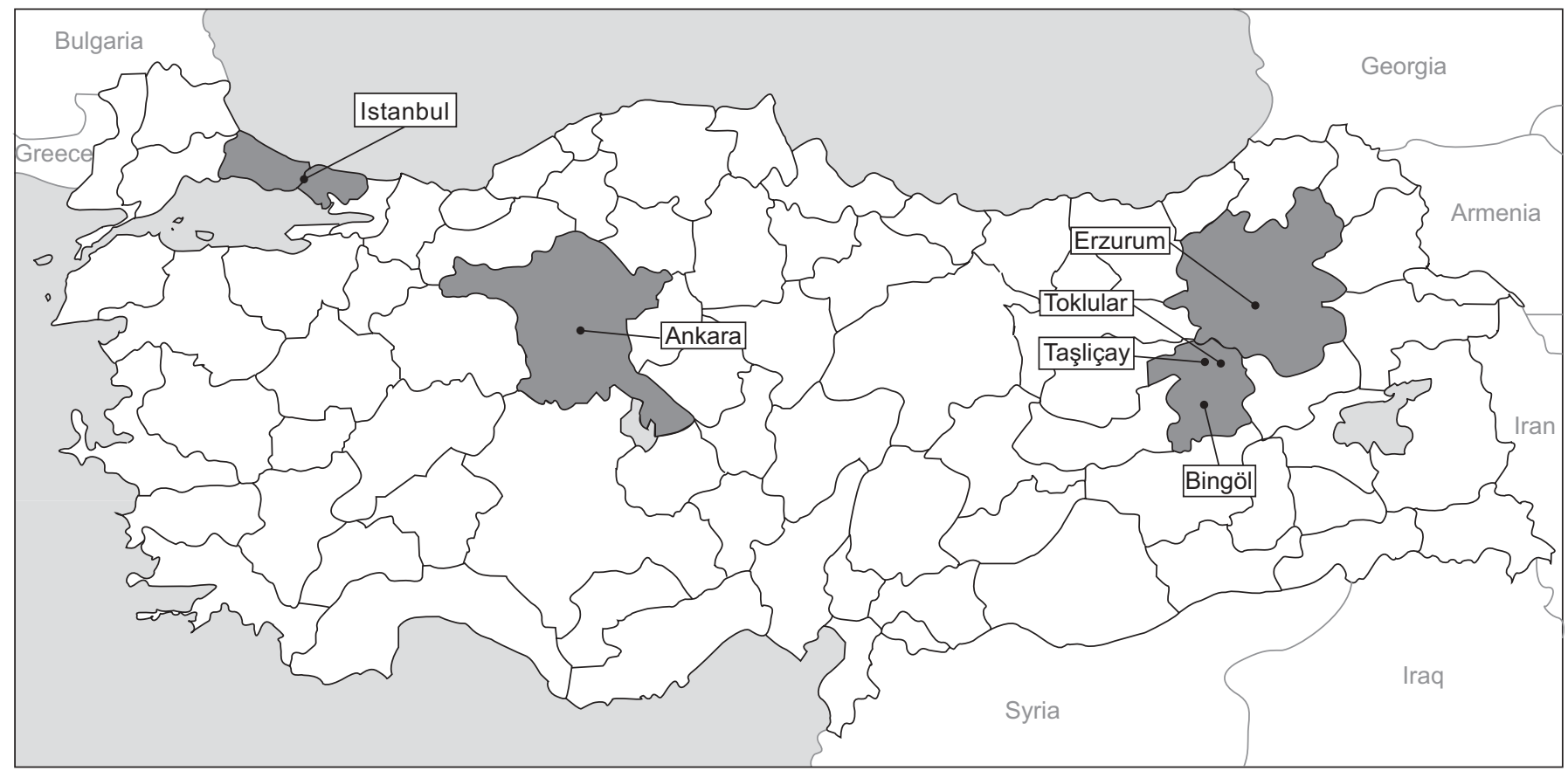

FIGURE 1. Map of Turkey showing the cities Bingöl, Erzurum, Ankara and Istanbul, and the villages Toklular and Taşliçay, which were involved in the study. Erzurum to Istanbul: 1,224 km; Erzurum to Toklular: $102 \mathrm{~km}$; Erzurum to Taşliçay: $105 \mathrm{~km}$. 
(FEV1), forced vital capacity (FVC) and FEV1/FVC ratio were recorded. FEV1 and FVC values were also expressed as \% of predicted value for age, sex and height [12].

Finally, posteroanterior chest radiographs of all the participants were taken at maximal inspiration, and these were later evaluated according to the International Labour Office (ILO) international classification of radiographs of pneumoconioses $[13,14]$. After initial evaluation by a radiologist (F. Alper) and a chest physician (M. Gorguner), the radiographs were evaluated by a chest physician (I. Akkurt), an experienced reader with 13 yrs experience in using the ILO classification, and a final consensus between the experts was reached.

Small opacities were classified into four main categories ( 0 to 3 ) and 12 subcategories, and the radiographs with $1 / 0$ or higher profusion were considered to indicate silicosis $[4,13,14]$. The ILO categories and subcategories were used as indices of disease severity. Further analysis was also performed by using the radiographs with $1 / 1$ or higher profusion as a criterion of silicosis.

\section{Statistical analysis}

Correlations between disease severity and the other parameters were calculated using Spearman's rank order correlation coefficients. Correlation between total exposure duration and number of places of work was calculated using Pearson's correlation coefficient. The Pearson Chi-squared test was used to compare categorical values. Multivariate analysis was performed using step-wise logistic regression analysis to determine which variables were independent risk factors for silicosis.

\section{RESULTS}

The present study included 157 male subjects who had worked in denim sandblasting between 1991 and 2006. In the studied population, the total number of workers employed by denimsandblasting companies increased substantially from the mid 1990s onwards, reaching a maximum in 2002 (fig. 2a).

Characteristics of the cases are presented in table 1 . The mean (range) age of subjects was $23(15-44)$ yrs. Two-thirds of subjects were smokers or ex-smokers, with a mean (range) cumulative smoking history of 7 (1-23) pack-yrs. Most subjects had started working in sandblasting before the age of $20 \mathrm{yrs}$ (fig. 2b), resulting in an age at first exposure of 17 (10-38) yrs. The total duration of work in sandblasting was, on average, 36 (1-120) months, and the mean (range) time since last exposure was 43 (10-144) months.

The information obtained from interviews with the workers can be summarised as follows. 1) No individuals were still actively working in this sector at the time of the study. Once it had been publicised that this form of work had caused fatal disease in a young male, all subjects ceased working in this sector. However, such workplaces are still in operation. In addition to Turkish workers, illegal immigrants from Romania, Azerbaijan, Georgia and other nations were employed in such workplaces. 2) Almost all of the cases were unregistered and uninsured. 3) Most of the workplaces where the subjects had been employed were unregistered or unlicensed (fig. 3). 4) In most workplaces, subjects worked in two shifts, day and night. While one group worked, the other group would sleep in an area behind a screen, where they were still exposed to the dust.
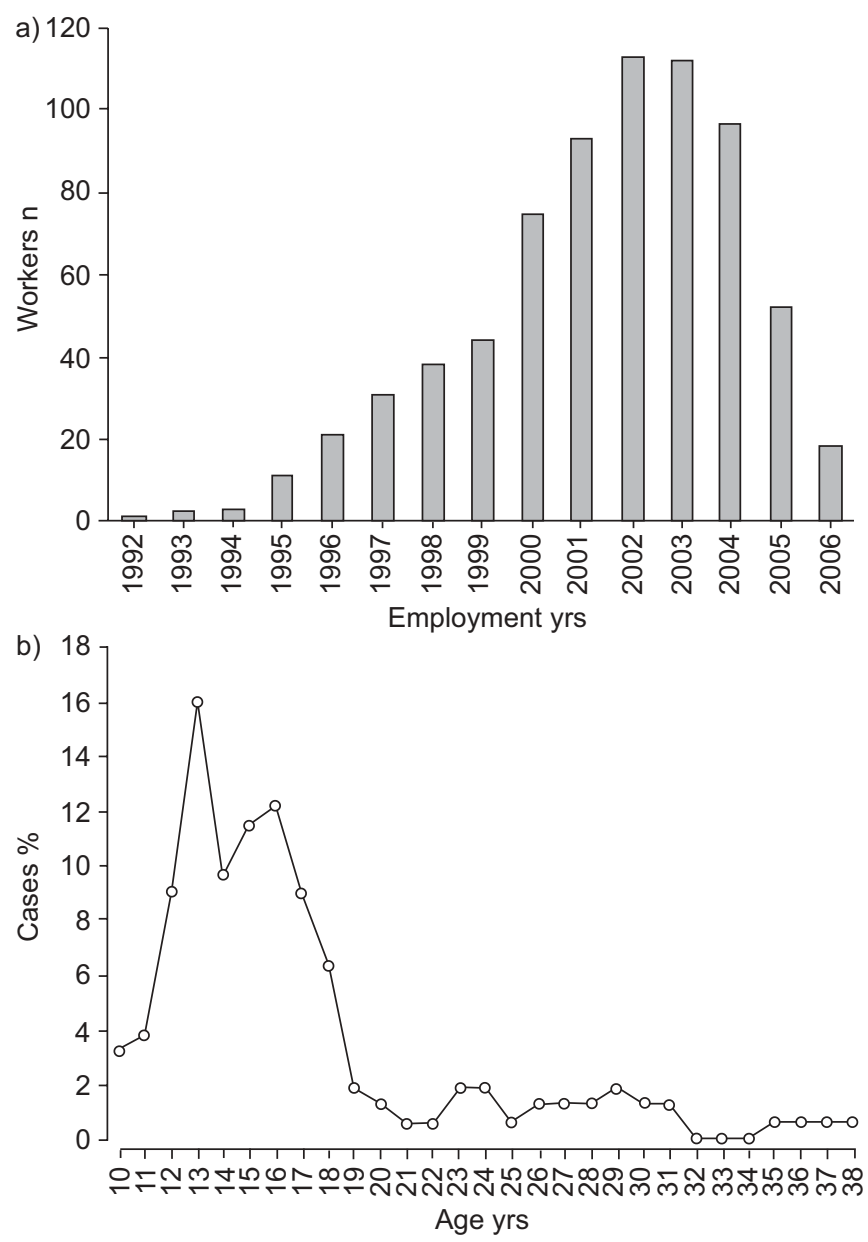

FIGURE 2. a) Number of subjects reported as employed in denim-sandblasting workshops in each calendar year. b) Distribution of age at first exposure of exworkers of denim sandblasting. Leaving employment due to mandatory military service may have accounted for the low number of workers around $20 \mathrm{yrs}$ of age. The first peak represents apprentices and the second represents foremen.

5) The subjects usually worked for $10 \mathrm{~h}$ each day, 6 days a week. Occasionally, when production orders were higher they would work $12 \mathrm{~h}$ each day, 7 days a week. 6) The number of sandblasted denim clothes produced varied depending on the size of clothing item. For example, a typical worker could sandblast 250-500 pairs of jeans a day and 3,000-5,000 skirts and other items of clothing (fig. 3). 7) The workers were generally provided with one mask a day (two masks in some places, none in some workplaces) to cover their mouths and noses while sandblasting. 8) Many workplaces used sifted sea sand and most workplaces had no ventilation. In some workplaces, to avoid wasting the sand, the doors and windows were tightly closed. 9) Within the workplace, workers had three ranks: apprentice, foreman and chief foreman. Younger workers would usually start as apprentices and be promoted to foremen after gaining a few months of experience. The chief foremen were usually workers with the most experience. The sandblasting was performed by the foremen, while the apprentices carried the material to the foremen and the chief foremen inspected the work. In one workplace with four sandblasting devices, there were eight foremen (working in 


\begin{tabular}{lc}
\hline TABLE 1 & $\begin{array}{l}\text { Demographic and exposure characteristics, and } \\
\text { pulmonary function test results in subjects with } \\
\text { previous experience in sandblasting }\end{array}$ \\
Subjects $\mathbf{n}$ & 157 \\
Age yrs & $23 \pm 6(15-44)$ \\
Age at first exposure to sandblasting yrs & $17 \pm 6(10-38)$ \\
Total exposure duration months & $36 \pm 25(1-120)$ \\
Duration since the last exposure months & $43 \pm 28(10-144)$ \\
Latency period ${ }^{\#}$ months & $79 \pm 35(12-192)$ \\
Number of places of work & $3 \pm 2(1-12)$ \\
Number of sandblasting devices at the & $4 \pm 1(2-12)$ \\
workplace & $106(67.5)$ \\
Smokers or ex-smokers & $7.3 \pm 4.4(1-23)$ \\
Smoking in smokers pack-yrs & $129(82.2)$ \\
Sleeping at the workplace & $126(80.3)$ \\
Working as a foreman & $33 \pm 28(0-117)$ \\
Seniority as a foreman months & $3.92 \pm 0.87$ \\
FEV1 L & $97.4 \pm 22.5$ \\
FEV1 \% pred & $4.53 \pm 0.93$ \\
FVC L & $95.6 \pm 21.9$ \\
FVC \% pred & $86.8 \pm 9.6$ \\
FEV1/FVC \% & \\
\hline
\end{tabular}

Data are presented as mean $\pm \mathrm{SD}$ (range), $\mathrm{n}(\%)$ or mean $\pm \mathrm{SD}$, unless otherwise stated. FEV1: forced expiratory volume in one second; \% pred: \% predicted; FVC: forced vital capacity. " ${ }^{\#}$ : time elapsed since the beginning of exposure.

two shifts), as many as eight apprentices and one to two chief foremen. 10) Although other methods were sometimes used to give a worn appearance to clothing (sandpaper, chemical procedures using potassium permanganate, and laser technology to produce drawings), sandblasting was the preferred method because it is quicker, more reliable and cheaper.

Based on the replies to the questionnaire, 131 (83\%) subjects were symptomatic (table 2). The most common symptom was dyspnoea $(n=81,52 \%)$ and chest pain was an unexpected, second most common symptom $(n=72,46 \%)$. Weight loss was also frequently reported $(n=24,15 \%)$, with an average loss of $10 \pm 5 \%$ (range $4.6-25 \%$ ) of total body weight. Nonrespiratory complaints, including upper airway and musculoskeletal complaints, were not uncommon.

All the subjects underwent chest radiography. However, two radiographs were unavailable during ILO reading and 10 radiographs were deemed to be of poor quality, thus 145 subjects were eligible for radiological evaluation. Of these, 77 $(53.1 \%)$ subjects were diagnosed with silicosis (fig. 4 ) on the basis of the presence of small opacities with a profusion of $1 / 0$ or more according to the ILO classification (table 3). Compared with the subjects without silicosis (table 4 ), those with silicosis had worked in more workplaces ( 3.0 versus $2.2, \mathrm{p}<0.05)$, for a longer duration (41 versus 32 months, $\mathrm{p}<0.05$ ), more frequently as foremen (95 versus $75 \%, \mathrm{p}<0.001$ ), for longer periods as foremen (46 versus 26 months, $\mathrm{p}<0.01$ ), and had a longer latency period (86 versus 73 months, $\mathrm{p}<0.05$ ). The number of sandblasting devices was significantly lower for workers with silicosis than those without silicosis (3.7 versus $4.2, \mathrm{p}<0.05$ ). Further analysis, in which a profusion of small opacities of $1 / 1$ or higher were used to indicate silicosis, showed that working as foreman (100 versus $76 \%, \mathrm{p}<0.001)$, duration of working as a foreman (50 versus 29 months, $\mathrm{p}<0.01$ ) and number of places of work (3.3 versus $2.2, \mathrm{p}<0.01)$ were significantly higher in 58 $(40 \%)$ subjects with silicosis compared with those without silicosis. However, when logistic regression analysis was applied, no independent risk factor emerged for silicosis, regardless of which of the two definitions of silicosis were adopted.

Subjects with silicosis had lower values of FEV1 and FVC, but a similar FEV1/FVC ratio than those without silicosis. Among subjects with silicosis, disease severity (defined according to ILO score) was significantly positively correlated with the number of places of work $(\mathrm{r}=0.32, \mathrm{p}<0.01)$, total exposure duration $(\mathrm{r}=0.25, \mathrm{p}<0.01)$ and, especially, the total exposure duration during work as a foreman $(r=0.48, p<0.001)$. In addition, total exposure duration was significantly correlated with number of places of work $(r=0.39, p<0.001)$. However, disease severity was significantly negatively correlated with all the pulmonary function test parameters ( $r$-values between -0.36 and $-0.46, \mathrm{p}<0.001$ ) except FEV1/FVC.

\section{DISCUSSION}

Denim (or jean) sandblasting has recently emerged as a new cause of silicosis, at least in Turkey. The main reason for the large number of cases in Erzurum is the high rate of unemployment, which causes the migration of workers, particularly young males, to larger cities looking for employment without any regard for the working conditions. All the subjects had moved to Istanbul with the help of a friend from their villages. Whenever one of the subjects found a job, they would then invite someone else to join them, thus establishing a chain process. With half the participating subjects (77 out of 157) having radiological evidence of silicosis, the frequency of disease in this group of subjects is alarmingly high, especially considering the relatively short exposure duration.

From 2000 onwards, the number of people working within the sandblasting profession showed a rapid increase. From 2004 onwards, several case reports of silicosis within this profession have been published [7-11]. The first cases proved difficult to diagnose because pneumoconiosis was not obviously associated with work in the textile sector. Little information was available about such workplaces, working conditions and the dust levels, thus making the management of the disease challenging. In the present study, some important aspects of the workplaces and the effects of the working conditions on workers' health were clarified. However, the dust levels and other characteristics (e.g. size and exact composition of particles) could not be evaluated. Nevertheless, considering the severe outcomes observed in the current study, it can be safely concluded that the dust levels in such workplaces must be very high. In addition, the cumulative exposure of these workers was probably also substantial as a result of long daily and weekly working patterns with, for some subjects, exposure while sleeping in the dusty workplaces. The young age of many of these workers may also be an aggravating factor.

In the present study, the diagnosis of pneumoconiosis was only based on chest radiograph findings in addition to exposure history. Although chest radiography remains the 

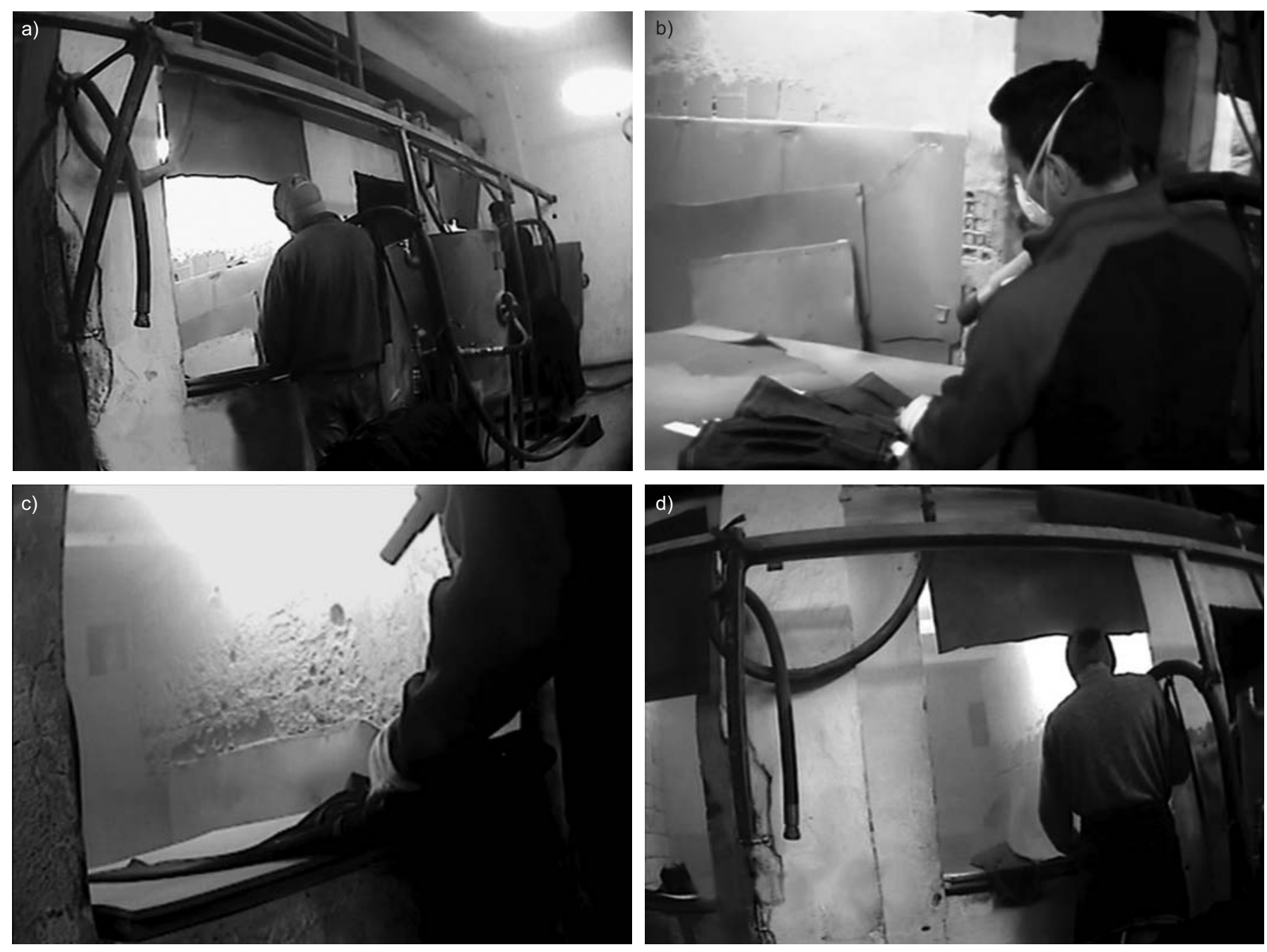

FIGURE 3. Images of the sandblasting process in workplaces. The number of sandblasting devices in each workplace varied between two and 12 . The number of clothing items sandblasted a day by one worker was as high as 5,000 depending on the size of the item. The pictures were obtained from a TV programme (ARENA) with kind permission from the programme Coordinators from two National Turkish Television Channels: Kanal D and CNN Turk.

\begin{tabular}{lc}
\hline TABLE 2 & $\begin{array}{l}\text { Symptoms in with a previous experience } \\
\text { in sandblasting }\end{array}$ \\
Subjects $\mathbf{n}$ & 157 \\
Asymptomatic & $26(16.6)$ \\
Symptomatic & $131(83.4)$ \\
Dyspnoea & $81(51.6)$ \\
Chest pain & $72(45.9)$ \\
Chronic cough & $30(19.1)$ \\
Weight loss & $24(15.3)$ \\
Malaise & $20(12.7)$ \\
Back pain & $17(10.8)$ \\
Sputum & $11(7.0)$ \\
Joint or extremity pain & $7(4.5)$ \\
Other complaints ${ }^{*}$ & $22(14.0)$ \\
\hline
\end{tabular}

Data are presented as $\mathrm{n}(\%)$, unless otherwise stated. *: eye complaints, nasal complaints (including epistaxis), hearing loss, mouth or throat dryness, headache, dizziness, diffuse pain and haemoptysis (decreasing in frequency). most convenient imaging modality to diagnose silicosis and to monitor its progression, the number of subjects with silicosis in the study group could be higher than detected because chest radiographs have some limitations for assessing pneumoconiosis [4]. Conventional or spiral computerised tomography $(\mathrm{CT})$, thin-section $\mathrm{CT}$ or combined use of $\mathrm{CT}$ and thin-section CT have been shown to detect cases that are undetectable by chest radiographs (ILO profusion score $<1 / 0)[15,16]$. This is partially supported by the higher rate of subjects with respiratory symptoms (83.4\%) than the rate of radiologically identified silicosis, bearing in mind that some participants may have had dust-induced bronchitis or that some may have exaggerated their symptoms because of anxiety. However, low-grade silicosis, only detected on CT, rarely causes respiratory symptoms and it is also possible that some radiologically diagnosed cases of silicosis were incorrect, since smoking, obesity or other lung conditions, such as TB or exposure to biomass, could have led to some false-positive diagnoses. Such misdiagnoses are unlikely to have been numerous. Although inhalation of cotton or other 

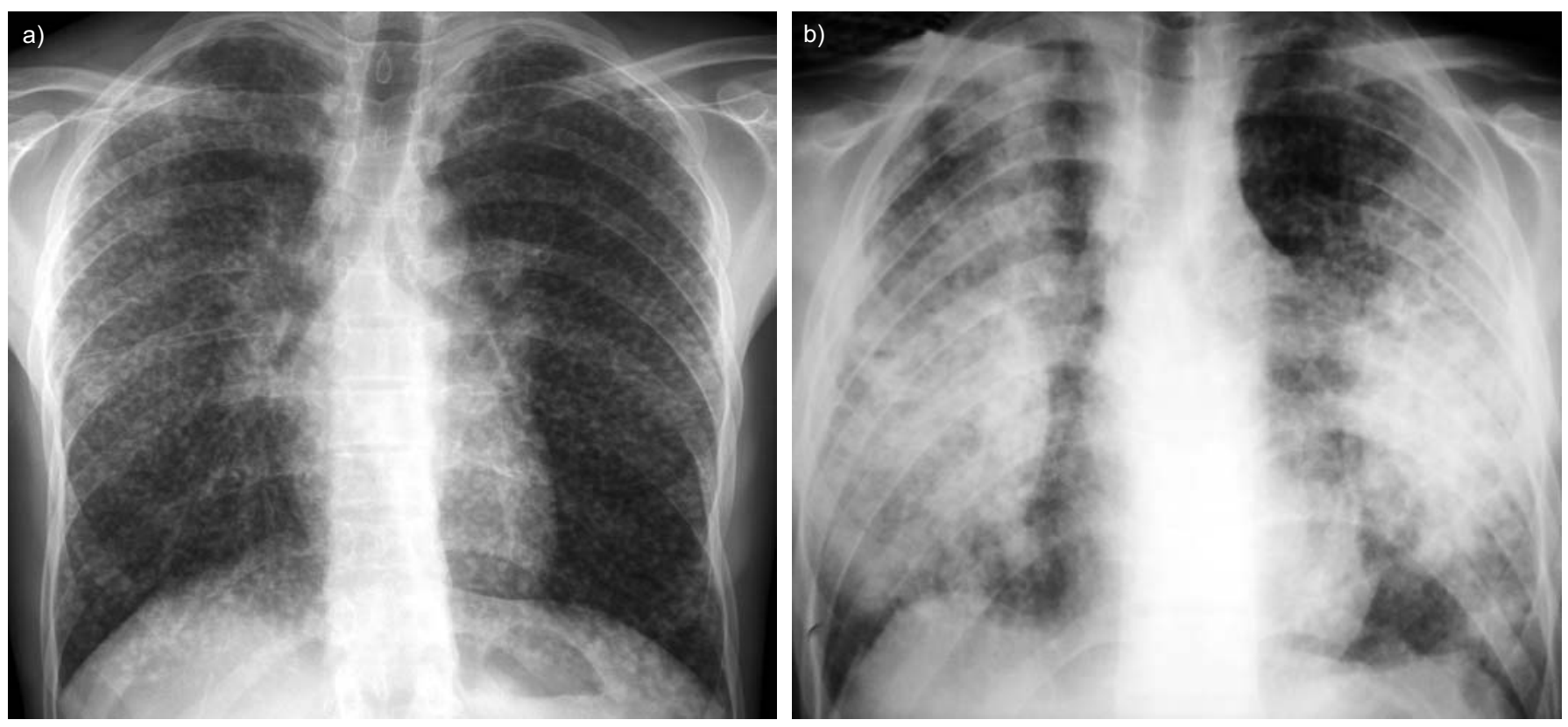

FIGURE 4. Chest radiographs belonging to two different ex-denim sandblasters showing a) bilateral small, widespread nodules and b) large type C opacities.

textile dust is a possibility, the magnitude and, thus, role of such exposure is likely to be small because the main aim of the sandblasting process is simply to fade the colour of the denim.
Workers who were exposed to high concentrations, longer duration of exposure $[17,18]$ and were younger $[17,19]$ were reported to be more likely to have more progressive radiographical findings than their counterparts. As indicated

TABLE 3 Chest radiograph results according to International Labour Office (ILO) classification in 145 subjects ${ }^{\#}$ with previous experience in sandblasting

\begin{tabular}{|c|c|c|c|}
\hline & Subjects & Total exposure duration months & Latency period" months \\
\hline \multicolumn{4}{|c|}{ Profusion of small opacities } \\
\hline 0/- & 52 & & \\
\hline $0 / 0$ & 3 & & \\
\hline $0 / 1$ & 13 & & \\
\hline $1 / 1$ & 9 & & \\
\hline $1 / 2$ & 7 & & \\
\hline Category 2 & $16(11.0)$ & $45 \pm 30$ & $92 \pm 36$ \\
\hline 2/1 & 4 & & \\
\hline 2/2 & 2 & & \\
\hline $2 / 3$ & 10 & & \\
\hline $3 /+$ & 12 & & \\
\hline Large opacities & $14(9.6)$ & & \\
\hline Type A & 6 & & \\
\hline Type B & 3 & & \\
\hline Type C & 5 & & \\
\hline
\end{tabular}

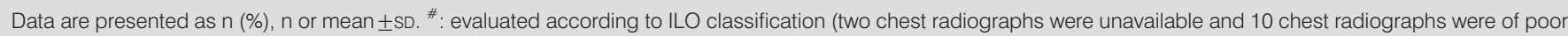
quality); ${ }^{\circ}$ : time elapsed since the beginning of exposure. 


\begin{tabular}{|c|c|c|c|c|}
\hline \multirow[t]{2}{*}{ TABLE 4} & \multicolumn{4}{|c|}{$\begin{array}{l}\text { Comparison of demographic and exposure characteristics and pulmonary function test results of subjects with or } \\
\text { without silicosis }\end{array}$} \\
\hline & & No silicosis & With silicosis & p-value \\
\hline \multicolumn{2}{|l|}{ Subjects n } & 68 & 77 & \\
\hline \multicolumn{2}{|l|}{ Age yrs } & $23 \pm 6$ & $23 \pm 5$ & 0.95 \\
\hline \multicolumn{2}{|c|}{ Age at first exposure to sandblasting yrs } & $17 \pm 6$ & $16 \pm 5$ & 0.28 \\
\hline \multicolumn{2}{|c|}{ Duration since the last exposure months } & $41 \pm 28$ & $44 \pm 28$ & 0.51 \\
\hline \multicolumn{2}{|c|}{ Latency period ${ }^{\#}$ months } & $73 \pm 34$ & $86 \pm 35$ & $<0.05$ \\
\hline \multicolumn{2}{|c|}{ Number of places of work } & $2.2 \pm 1.3$ & $3.0 \pm 0.7$ & $<0.05$ \\
\hline \multicolumn{2}{|c|}{ Number of sandblasting devices at the workplace } & $4.2 \pm 1.5$ & $3.7 \pm 0.7$ & $<0.05$ \\
\hline \multicolumn{2}{|c|}{ Smokers or ex-smokers } & $43(63)$ & $57(74)$ & 0.16 \\
\hline \multicolumn{2}{|c|}{ Smoking in smokers pack-yrs } & $6.8 \pm 4.3$ & $7.9 \pm 4.6$ & 0.23 \\
\hline \multicolumn{2}{|l|}{ FEV 1 L } & $4.22 \pm 0.71$ & $3.66 \pm 0.96$ & $<0.001$ \\
\hline \multicolumn{2}{|l|}{ FEV1 \% pred } & $105.6 \pm 18.7$ & $89.8 \pm 23.4$ & $<0.001$ \\
\hline \multicolumn{2}{|l|}{ FVC L } & $4.84 \pm 0.74$ & $4.27 \pm 1.04$ & $<0.001$ \\
\hline \multicolumn{2}{|l|}{ FVC \% pred } & $103.4 \pm 19.9$ & $88.5 \pm 21.1$ & $<0.001$ \\
\hline \multicolumn{2}{|l|}{$\mathrm{FEV}_{1 / \mathrm{FVC}} \%$} & $87.6 \pm 9.5$ & $86.3 \pm 9.5$ & 0.44 \\
\hline
\end{tabular}

previously, the cases diagnosed as silicosis in the present study had longer exposure duration and possibly high cumulative exposures. Although all three types of work (apprentice, foreman and chief foreman) were exposed either through their own sandblasting device or that of others, it appeared that only the primary exposure of the foremen (fig. 3) was highly associated with the development of silicosis. In addition, total exposure duration and especially the exposure duration as a foreman were highly correlated with silicosis development. Although younger age has been shown as a risk factor for the development of silicosis, such association could not be established in the current study, which may have been because the youngest subjects were working as apprentices and they had no primary or heavy exposure, as did the foremen. Thus, they only had secondary exposures. Nevertheless, younger age may be responsible for the high frequency of silicosis found in denim sandblasters due to intrinsic factors, such as incomplete maturation of clearance systems or an incomplete lung growth, or due to extrinsic factors including general lack of work experience, unawareness of workplace hazards and how they can be avoided, or eagerness to do well at work. However, it is not clear which factors are more responsible for the development of silicosis in younger workers. As most of the study subjects were young, the manifestation of silicosis in some cases might be explained by predominance of risk factors other than age.

The other parameters that were associated with disease severity were increased number of places of work and decreased number of sandblasting devices in the workplace. It is reasonable to consider that not all workplaces had equal dust levels because their size, the number of sandblasting devices, ventilation systems, working hours and other protective measurements may vary. The higher the number of places of work, the higher the probability of having worked in places with poor working conditions; thus, some of the workers may have continually changed their workplaces. The apparent paradox that the number of sandblasting devices was inversely related to the risk of silicosis can be explained by the fact that workplaces with more devices are not only more spacious (hence lower dust concentration) but also provide better working conditions because unregistered or uninsured workers cannot be employed in workplaces with more sandblasting devices and larger workplaces are more difficult to keep concealed from inspections.

As expected, the main symptom in the study group was dyspnoea because it is the main symptom of silicosis. This was first noted during exertion and then later at rest. Chest pain and weight loss are unusual characteristics of silicosis, and are mostly attributed to the other conditions that may be associated with silicosis, such as TB and lung cancer [20], but they were prominent in some of the study subjects. Although the present authors have previously encountered some cases of TB, misdiagnosed [7] or bacteriologically proven, in the current study, the cases for TB were not evaluated. Back, joint and extremity pain were also detected. It can be speculated that chest or back pain may be associated with pleural involvement and/or traction of parenchymal fibrosis. However, it is also possible that these symptoms were associated with musculoskeletal problems resulting from poor ergonomic conditions. Other interesting findings were nonrespiratory symptoms, such as eye, nasal and ear problems. These symptoms are more likely to be underestimated due to the predominant respiratory 
and pulmonary symptoms. Lack of protective measures, except a simple mouth-nasal mask, and the loud noise in the workplaces may account for the development of such symptoms.

Radiological disease severity was strongly correlated with both FEV1 and FVC but not with FEV1/FVC, thus strengthening the plausibility of the radiological findings. Some studies have shown association between deteriorating lung function and nodular profusion and coalescence [21,22]. As the present study group was mainly composed of light-to-moderate smokers, these changes may be attributed to silica exposure alone.

Further analysis was performed using a stricter cut-off value for silicosis (profusion of small opacities of $1 / 1$ or higher) as it has been shown that a significant number $(\leqslant 11 \%)$ of subjects without known exposure to dust have $1 / 0$ small opacities [23]. This approach is sometimes used to increase specificity at the expense of decreased sensitivity [23, 24]. With this approach, the present case numbers decreased from 77 (53\%) to 58 (40\%), fewer parameters were found to be significant (working as foreman, duration of working as foreman and number of places of work), but no single independent risk factor emerged again. Nevertheless, the number of cases with silicosis remained very high.

The current study also has some limitations. The authors were not able to recruit everyone who had worked in sandblasting in the two villages, and it is conceivable that the more affected subjects visited the clinic at Atatürk University. The authors tried to prevent such a selection bias by inviting all exposed subjects to participate and providing free transport and procedures. By doing so it was possible to recruit a reasonably high proportion of the target population (157 subjects out of an estimated 500), with those not attending often simply being away from home at the time of the survey. The fact that only 14 out of the 49 already diagnosed cases attended the survey pleads somewhat against a major selection bias towards participation by the most affected subjects. The present study group may not represent the whole population of denim sandblasters. The workers from the two villages may have worked in workplaces with worse conditions or they may have started at a younger age than those from other regions, or they may even have some genetic predisposition to developing the disease. However, there are no indications for any of these possibilities. Thus, although selection bias cannot be excluded and may have somewhat distorted the association between silicosis and denim sandblasting, this does not invalidate the present findings which show a high frequency of silicosis among denim sandblasters. Another limitation of the present study is lack of knowledge on the exact dust types, and the contents of and concentrations in the workplaces. Although it was not possible to obtain such information, it would be very difficult to reach valid conclusions because many workplaces have different sizes and working conditions. This heterogeneity may also be responsible for the absence of any independent risk factor among the study parameters.

Although whole-lung lavage may be used with the aim of slowing disease progression by removing large quantities of dust particles, inflammatory cells and cytokines from the lung [25], and although lung transplantation may be an option for patients with end-stage disease, silicosis is still considered incurable. Therefore, focusing on exposure prevention to silica is essential
$[1,2,26]$. However, this is difficult because there are several problems that need to be solved that hinder prevention, including: the rapid growth in the textile sector; the high rate of unemployment; and the lack of awareness of the employers and employees [27]. In addition, a serious problem is the lack of inspection of such workplaces. At the 2006 Annual Congress of the Turkish Thoracic Society, this issue was extensively evaluated, with contributions from the officials of the Turkish Ministry of Labor [9]. In 2007, the Turkish Ministry of Labor prepared a national programme for the prevention of pneumoconiosis to be piloted in denim sandblasting areas [28]. However, the objectives described in the programme (increasing social awareness up to 2010 and achieving full management of the issue by 2015) are too modest and will not provide an early solution to the problem. Due to the high risk of silicosis in sandblasters and the difficulty in controlling exposures, the use of crystalline silica for blast-cleaning operations was prohibited in the UK in 1950 [29] and in other European countries in 1966; this legislative measure has been followed by a reduction in silicosis incidence.

In addition, although no cases have been reported from other countries so far, the problem of denim sandblasting should not be considered as unique to Turkey. It is not impossible that the tip of a more global iceberg has been described. As indicated previously, there are workers from many countries working in Turkish textile factories and workshops, and it is likely that this type of "technology" will be applied in other countries with poor implementation of health and safety at work. Another global concern is that most of the sandblasted denim is worn outside of Turkey.

In conclusion, the epidemic of silicosis due to exposure to silica in sectors such as denim sandblasting may exceed the estimations. Although the present authors were only able to establish contact with a small proportion of the ex-workers, the evaluations revealed a significant effect of silica exposure. At present, there are no active working individuals in this sector; thus, the storms appeared to have calmed. Considering the number of workers that could not be contacted (in Erzurum and nationwide), the number of workers with under-recognised disease but with no radiological manifestation as yet, the number of currently operating sandblasting factories, and the size of the textile industry in Turkey and its continuing trend for expansion, a problem of greater magnitude and severity may be inevitable unless effective measures are taken urgently.

\section{ACKNOWLEDGEMENTS}

The authors would like to thank: M. Gölen, the mayor of Karliova (Turkey); the producers of the ARENA television programme, U. Dündar (programme host), H. Demircan (programme reporter), and M. Sis and C. Erçin (camermen); and the staff of the Dept of Radiology and Chest Diseases (Atatürk University, Aziziye Research and Teaching Hospital, Erzurum, Turkey). The authors also thank S. Ugur (Dept Modern Languages, Middle East Technical University, Ankara, Turkey) for editorial help.

\section{REFERENCES}

1 Rees D, Murray J. Silica, silicosis and tuberculosis. Int $J$ Tuberc Lung Dis 2007; 11: 474-484.

2 Wagner GR. Asbestosis and silicosis. Lancet 1997; 349: 1311-1315. 
3 Wagner GR. The inexcusable persistence of silicosis. Am J Public Health 1995; 85: 1346-1347.

4 Ooi CGC, Arakawa H. Silicosis. In: Gevenois PA, De Vuyst $\mathrm{P}$, eds. Imaging of Occupational and Environmental Disorders of the Chest. Springer, Berlin, 2006; pp. 177-193..

5 Xiao GB, Morinaga K, Wang RY, Zhang X, Ma ZH. World at work: manufacturing "tatami" mats in China. Occup Environ Med 2004; 61: 372-373.

6 de la Hoz RE, Rosenman K, Borczuk A. Silicosis in dental supply factory workers. Respir Med 2004; 98: 791-794.

7 Akgun M, Gorguner M, Meral M, et al. Silicosis caused by sandblasting of jeans in Turkey: a report of two concomitant cases. J Occup Health 2005; 47: 346-349.

8 Akgun M, Mirici A, Yilmazel Ucar E, Kantarci M, Araz O, Gorguner M. Silicosis in Turkish denim sandblasters. Occup Med 2006; 56: 554-558.

9 Çimrin A, Sigsgaard T, Nemery B. Sandblasting jeans kills young people. Eur Respir J 2006; 28: 885-886.

10 Sahbaz S, Inonu H, Ocal S, et al. Denim sandblasting and silicosis: two new subsequent cases in Turkey. Tuberk Toraks 2007; 55: 87-91.

11 Horzum G, Oruc K, Calisir HC. Diagnosis through occupational history: a case of silicosis caused by sand rodeo. Akciger Dergisi 2006; 12: 183-187.

12 Quanjer PH, Tammeling GJ, Cotes JE, Pedersen OF, Peslin R, Yernault JC. Lung volumes and forced ventilatory flows. Report Working Party Standardization of Lung Function Tests European Community for Steel and Coal. Eur Respir J 1993; 6: Suppl. 16, 5-40.

13 International Labour Office (ILO). Guidelines for the use of the ILO International Classification of Radiographs of Pneumoconioses. Revised Edition. ILO occupational safety and health series. No. 22 (rev 80). Geneva, 1980.

14 International Labour Office (ILO). Guidelines for the use of the ILO International Classification of Radiographs of Pneumoconioses. Revised Edition. ILO occupational safety and health series. No. 22 (rev), Geneva, 2000.

15 Begin R, Ostiguy G, Fillion R, Colman N. Computed tomography in the early detection of silicosis. Am Rev Respir Dis 1991; 144: 697-705.

16 Gevenois PA, Pichot E, Dargent F, et al. Low grade coal worker's pneumoconiosis. Comparison of CT and chest radiography. Acta Radiol 1994; 35: 351-356.
17 Hughes JM, Jones RN, Gilson JC, et al. Determinants of progression in sandblasters' silicosis. Ann Occup Hyg 1982; 26: 701-712.

18 Miller BG, Hagen S, Love RG, et al. Risks of silicosis in coalworkers exposed to unusual concentrations of respirable quartz. Occup Environ Med 1998; 55: 52-58.

19 Lee HS, Phoon WH, Ng TP. Radiological progression and its predictive risk factors in silicosis. Occup Environ Med 2001; 58: 467-471.

20 Cowie RL, Murray J, Becklake MR. Pneumoconioses. In: Mason RJ, Murray JF, Broaddus VC, Nadel JA, eds. Murray \& Nadel's Textbook of Respiratory Medicine. 4th Edn. Saunders, Philadelphia, 2005; pp. 1748-1782.

21 Bergin CJ, Müller NL, Vedal S, Chang-Yeung M. CT in silicosis: correlation with plain films and pulmonary function tests. AJR Am J Roentgenol 1986; 146: 477-483.

22 Ooi GC, Tsang KW, Cheung TF, et al. Silicosis in 76 men: qualitative and quantitative CT evaluation: clinical-radiologic correlation study. Radiology 2003; 228: 816-825.

23 >Epstein DM, Miller WT, Bresnitz EA, Levine MS, Gefter WB. Application of ILO classification to a population without industrial exposure: findings to be differentiated from pneumoconiosis. AJR Am J Roentgenol 1984; 142: 53-58.

24 Akkurt I, Onal B, Demir AU, et al. Respiratory health in Turkish asbestos cement workers: the role of environmental exposure. Am J Ind Med 2006; 49: 609-616.

25 Wilt JL, Banks DE, Weissman DN, et al. Reduction of lung dust burden in pneumoconiosis by whole-lung lavage. Occup Environ Med 1996; 38: 619-624.

26 De Vuyst P, Camus P. The past and present of pneumoconioses. Curr Opin Pulm Med 2000; 6: 151-156.

27 Çimrin A. "Silicosis" over again; causes and responsibilities. Tuberk Toraks 2007; 55: 118-122.

28 Ulusal Pnomokonyoz Onleme Eyleme Plani. [National pneumoconiosis prevention action plan.] www.isggm. gov.tr/files/pnomokonyoz/1_ulusal_pnomokonyoz_onlemeeylem_plani.pdf Date last accessed: July 2, 2007.

29 Ministry of Labour and National service, Factories Act, 1937 and 1948-blasting (castings and other articles) special regulations. Factory Department, SI 1949. No. 2225. London, 1949; pp. 4331-4335. 